\title{
Inhibitory Effect of Anti-Inflammatory Agents on Cutaneous Capillary Leakage Induced by Six Marine Venoms
}

\author{
Kazuo Shiomi, * Katsuyuki Nagai, ${ }^{*}$ Hideaki Yamanaka,* \\ and Takeaki Kikuchi*
}

(Received July 5, 1988)

\begin{abstract}
Anti-inflammatory agents were surveyed for their inhibitory effect on the cutaneous capillary leakage induced by venoms from the following six marine animals: the stonefish Synanceja verrucosa, the crown-of-thorns starfish Acanthaster planci, the Portuguese man-of-war Physaliaphysalis, the sea anemone Actinodendron plumosum and two species of fire corals Millepora platyphylla and $M$. dichotoma. The capillary permeability-increasing action of $A$. planci and $A$. plumosum venoms was significantly reduced by $\mathrm{H}-1$ antihistaminics, diphenhydramine and pyrilamine maleate, while none of the anti-inflammatory agents were effective for the other venoms. HPLC analyses established the absence of histamine in both $A$. planci and $A$.plumosum venoms. Instead, the $A$. planci venom was shown to release histamine from rat mast cells. Thus, the following pathogenic mechanism was assumed to exert in the capillary damage by the 1. planci venom: a histamine-releasing factor in the venom first acts on mast cells (and other cells) and then the released histamine produces the increase in capillary permeability.
\end{abstract}

A number of marine animals contain proteinaceous venoms in specialized venom apparatus such as spines and nematocysts. When stung by these animals, pain, swelling, redness and others are immediately evoked in the skin of victims in most cases. At least a part of these local effects in the skin seem to be manifestations of the capillary permeability-increasing activity of venoms. Therefore, in order to protect the skin against marine venoms, it is important to find a preferable anti-inflammatory agent capable of inhibiting the cutaneous capillary leakage induced by venoms. Along this line, various anti-inflammatory agents have been previously surveyed by Burnett and Calton ${ }^{1)}$ for their inhibitory effect on the vasopermeability action of venoms from four species of coelenterates. Although a few drugs were found to be effective to some extent, no single antagonist could block the vasopermeability action of the coelenterate venoms.

In the present paper we describe a survey of useful anti-inflammatory agents toward the cutaneous capillary leakage induced by venoms from the following six species of marine animals: the stonefish Synanceja verrucosa, the crown-of-thorns starfish Acanthaster planci, the Portuguese manof-war Physalia physalis, the sea anemone $A C$ tinodendron plumosum and two species of fire corals Millepora platyphylla and $M$. dichotoma. The presence of a histamine-releasing factor in $A$. planci venom is also described.

\section{Materials and Methods}

\section{Animals}

Specimens of $S$. verrucosa, M. platyphylla and $M$. dichotoma were collected along the coast of Kuroshima Island, Okinawa Prefecture, in March 1987, and those of $A$. planci and $A$. plumosum at Kabira, Ishigaki Island, Okinawa Prefecture, in October 1986. They were frozen immediately after collection, shipped with ice to our laboratory and kept at $-20^{\circ} \mathrm{C}$ until used. Specimens of $P$. physalis were collected at Enoshima, Kanagawa Prefecture, in June 1987 and transported to our laboratory, where tentacles were cut off from the animals and stored at $-20^{\circ} \mathrm{C}$ until used.

\section{Extraction of Venom}

Venom (about $0.1 \mathrm{~m} l$ ) of $S$. verrucosa was collected with a syringe from a venom sac in the dorsal spine and diluted with $2 \mathrm{ml}$ of buffered saline $(0.15 \mathrm{M} \mathrm{NaCl}$ in $0.01 \mathrm{~m}$ phosphate buffer, pH 7.0) containing $1 \% 2$-mercaptoethanol. Although significant amounts of insoluble materials were observed, the homogeneous suspension was

* Department of Food Science and Technology, Tokyo University of Fisheries, Konan, Minato, Tokyo 108, Japan (塩見一雄, 長井克之, 山中英明, 菞池武昭: 東京水崖大学食品生摩学科). 
obtained after shaking briefly. Spines of $A$. planci, tentacles of $P$. physalis and whole bodies of $A$. plumosum were homogenized in 2 volumes of $0.01 \mathrm{M}$ phosphate buffer ( $\mathrm{pH} 6.8), 3$ volumes of buffered saline and 2 volumes of buffered saline, respectively. Each homogenate was centrifuged at $15000 \mathrm{rpm}$ for $15 \mathrm{~min}$ and the supernatant was used as venom solution. In the case of fire corals, the surface of each specimen (about $25 \mathrm{~g}$ ) was scraped off with a scalpel and the material obtained was extracted with $3 \mathrm{ml}$ of $0.01 \mathrm{M}$ phosphate buffer $(\mathrm{pH} 7.0)$. The protein concentrations of the venom solutions from $S$. verrucosa, A. planci, $P$. physalis, A. plumosum, $M$. platyphylla and $M$. dichotoma, which were determined by the method of Lowry et al.,2) were 3.3, 5.2, 12.8, 10.3, 2.8 and $2.0 \mathrm{mg} / \mathrm{m} /$, respectively.

\section{Assay of Capillary Permeability-Increasing Activity}

Each $0.1 \mathrm{~m} l$ of venom solution (or its diluted solution) was injected intradermally into the depilated back skin of Wistar male rats weighing $180-200 \mathrm{~g}$ and then $0.1 \mathrm{ml}$ of $1 \%$ Evans Blue solution was injected intravenously to trace permeability changes. After $2 \mathrm{~h}$, the rats were sacrificed and the diameter of each blue wheal produced was measured from the visceral side. The activity of histamine was also determined.

\section{Assay of Edema-Forming Activity}

Edema-forming activity was estimated using ddY male mice weighing about $20 \mathrm{~g}$ by the method of Yamakawa et al. ${ }^{3)}$ Groups of five mice were injected with $25 \mu l$-aliquots of venom solution in the right foot pad and with $25 \mu \mathrm{l}$-aliquots of buffered saline in the left foot pad. After $2 \mathrm{~h}$, both feet were cut off from the mice sacrificed and their weights were compared. Edema ratio was defined as the percentage in weight of the envenomated foot relative to the saline injected foot.

\section{Inhibition Test by Anti-Inflammatory Agents}

The anti-inflammatory agents used were as follows: diphenhydramine (H-1 antihistaminic), pyrilamine maleate $(\mathrm{H}-1$ antihistaminic), cimetidine (H-2 antihistaminic), indomethacin (anti-prostaglandin analgesic), ibuprofen (anti-prostaglandin analgesic) and phenylbutazone. These drugs were injected intraperitoneally into rats or mice at the following doses: $10 \mathrm{mg} / \mathrm{kg}$ for diphenhydramine, $50 \mathrm{mg} / \mathrm{kg}$ for pyrilamine maleate, $30 \mathrm{mg} /$ $\mathrm{kg}$ for cimetidine, $10 \mathrm{mg} / \mathrm{kg}$ for indomethacin, $17 \mathrm{mg} / \mathrm{kg}$ for ibuprofen and $100 \mathrm{mg} / \mathrm{kg}$ for phenylbutazone. After $1 \mathrm{~h}$, capillary permeability-in- creasing activity of each venom or histamine was determined using the rats and edema-forming activity of $A$. planci venom using the mice.

\section{Determination of Amines in Venoms}

Spines of $A$. planci and whole bodies of $A$. plumosum were individually extracted with an equal volume of $10 \%$ perchloric acid. Each extract was determined for amines by high perfor. mance liquid chromatography (HPLC) on a Shim-pack CLC-ODS $(0.6 \times 15 \mathrm{~cm}$, Shimadzu), essentially in the same manner as reported previously. ${ }^{4)}$ The standard amines used were agmatine, cadaverine, histamine, putrescine, serotonin, spermidine, tryptamine and tyramine.

\section{Determination of Histamine Released from Rat Mast Cells}

Six rats were decapitated, exanguinated and injected intraperitoneally with $8 \mathrm{ml}$ of $0.01 \mathrm{M}$ phosphate buffer ( $\mathrm{pH} 7.2$ ) containing $0.15 \mathrm{M} \mathrm{NaCl}$, $3 \mathrm{mM} \mathrm{KCl}, 1 \mathrm{mM} \mathrm{CaCl} 2$ and $0.05 \%$ bovine serum albumin. The abdomen was massaged for $90 \mathrm{~s}$ and the peritoneal fluid was collected through a middle incision. The fluid was centrifuged at $700 \mathrm{rpm}$ for $5 \mathrm{~min}$ and the mast cell pellet was resuspended in $2 \mathrm{~m} l$ of the above phosphate buffer without bovine serum albumin. To $0.1 \mathrm{~m} /$ of the suspension was added $0.1 \mathrm{~m} I$ of $A$. planci venom and the mixture was incubated at $37^{\circ} \mathrm{C}$ for $5 \mathrm{~min}$. The reaction was terminated by cooling in an ice-water bath and the mixture was centrifuged at $700 \mathrm{rpm}$ for $5 \mathrm{~min}$. To the supernatant was added an equal volume of $2 \mathrm{~N}$ perchloric acid. After centrifugation at $2500 \mathrm{rpm}$ for $5 \mathrm{~min}$, the supernatant obtained was determined for histamine by HPLC. In order to estimate the total histamine contained in the cells, $0.3 \mathrm{~m} l$ of $2 \mathrm{~N}$ perchloric acid was added to $0.1 \mathrm{~m} l$ of the cell suspension. The mixture was boiled for $10 \mathrm{~min}$, centrifuged at $2500 \mathrm{rpm}$ for $5 \mathrm{~min}$ and the resulting supernatant was analyzed by HPLC.

\section{Results and Discussion}

\section{Inhibition of Capillary Permeability-Increasing} Activity by Anti-Inflammatory Agents

All tested venoms showed capillary permeability. increasing activity. As shown in Table 1 , the cutaneous capillary leakage induced by $A$. planci venom was significantly reduced by the $\mathrm{H} \cdot \mathrm{l}$ antihitaminics, diphenhydramine and pyrilamine maleate, while it was neither blocked nor enhanced by the other drugs. Similarly, only diphenhy. 
Table 1. Effect of anti-inflammatory agents on the cutaneous capillary leakage induced by six marine venoms and histamine

\begin{tabular}{|c|c|c|c|c|c|c|c|}
\hline \multirow{2}{*}{$\begin{array}{c}\text { Anti- } \\
\text { inflammatory } \\
\text { agent }\end{array}$} & \multicolumn{7}{|c|}{ Diameter of blue wheal in $\mathrm{mm}$ (mean \pm S.D., $\mathrm{n}=6$ or 9 ) } \\
\hline & $\begin{array}{c}S . \\
\text { verrucosa } \\
(11 \mu \mathrm{g})^{*}\end{array}$ & $\begin{array}{c}\text { A. } \\
\text { planci } \\
(130 \mu \mathrm{g})\end{array}$ & $\begin{array}{c}P . \\
\text { physalis } \\
(320 \mu \mathrm{g})\end{array}$ & $\begin{array}{c}\text { A. } \\
\text { plumosum } \\
(110 \mu \mathrm{g})\end{array}$ & $\begin{array}{c}M . \\
\text { platyphylla } \\
(70 \mu \mathrm{g})\end{array}$ & $\begin{array}{c}M . \\
\text { dichotoma } \\
(50 \mu \mathrm{g})\end{array}$ & $\begin{array}{r}\text { Histamine } \\
(10 \mu \mathrm{g})\end{array}$ \\
\hline Control & $10.1 \pm 1.4$ & $10.1 \pm 0.8$ & $10.1 \pm 1.2$ & $10.5 \pm 0.9$ & $11.0 \pm 1.1$ & $11.2 \pm 1.1$ & $9.8 \pm 0.4$ \\
\hline Diphenhydramine & $10.0 \pm 0.8$ & $6.7 \pm 0.9$ & $10.0 \div 0.8$ & $5.4 \pm 0.5$ & $10.2 \pm 0.7$ & $11.1 \pm 0.9$ & $5.4 \pm 0.5$ \\
\hline Pyrilamine & & $6.9 \pm 0.8$ & & & $10.7 \pm 0.3$ & & \\
\hline Cimetidine & $11.0 \pm 1.3$ & $10.5 \pm 1.4$ & $10.3 \pm 0.8$ & $10.6 \pm 0.8$ & $10.6 \pm 0.2$ & $11.3 \pm 0.9$ & \\
\hline Indomethacin & $10.3 \pm 1.7$ & $10.9 \pm 1.1$ & $10.1 \pm 1.6$ & $10.2 \pm 0.9$ & $11.2 \pm 0.7$ & $11.3 \pm 1.1$ & \\
\hline Ibuprofen & $10.6 \pm 1.7$ & $11.1 \pm 0.8$ & $10.4 \pm 0.9$ & $10.6 \pm 0.7$ & $11.5 \pm 1.3$ & $11.4 \pm 0.8$ & \\
\hline Phenylbutazone & $10.0 \pm 1.1$ & $10.8 \pm 0.6$ & $10.5 \pm 0.2$ & $10.7 \pm 0.6$ & $11.1 \pm 0.7$ & $11.5 \pm 1.4$ & \\
\hline
\end{tabular}

* Doses are indicated in parentheses.

dramine was effective to counteract the vasopermeability acition of $A$. plumosum venom, although pyrilamine maleate was not tested. It is interesting that the inhibitory effects of diphenhydramine on the cutaneous capillary leakage induced by these two venoms were comparable to the result with histamine used as a reference. Thus, it is obvious that histamine is involved in the vasopermeability action of the two venoms. However, histamine does not appear to be a major contributor to the the edema-forming action of $A$. planci venom. The $\mathrm{H}-1$ antihistaminics as well as the other drugs did not reduce the edema formation by the venom. The capillary permeability-increasing activity and edema-forming activity of $A$. planci venom seem to be displayed by different pathogenic mechanisms.

In contrast to the results with the above two venoms, no effective anti-inflammatory agent could be found for the cutaneous capillary leakage induced by $S$. verrucosa, $P$. physalis, $M$. platyphylla and $M$. dichotoma venoms. Histamine seems to have no relation at all to the vasopermeability action of these venoms. Burnett and Calton ${ }^{1)}$ previously reported that diphenhydramine has no potency to couteract the increase in vasopermeability induced by venoms from four species of coelenterates, Bolocera tuediae, Chironex fleckeri, Chrysaora quinquecirrha and $P$. physalis. Instead, methylsergide, an anti-serotonin agent, was shown to be the most useful therapeutic drug for C. fleckeri, C. quinquecirrha and $P$. physalis venoms; a few other agents were also effective for the venoms to some extent, for example, indomethacin for $C$. fleckeri venom. The capillary damage induced by $S$. verrucosa, $M$. platyphylla and $M$. dichotoma venoms may be reduced by methylsergide. Concerning the stonefish venom, it should be pointed out that a specific antivenom has been developed ${ }^{5,8)}$ and put to practical use. It is interesting to examine whether the capillary damage induced by stonefishes including $S$. verrucosa can be neutralized by the antivenom.

The present study, together with that of Burnett and Calton, ${ }^{1)}$ led us to assume that various pathogenic mechanisms exert in the cutaneous capillary leakage induced by marine venoms. Therefore, as pointed out by Burnett and Calton, ${ }^{1)}$ future anti-venom therapy should be venomspecific. Further study is needed to find a specific anti-inflammatory agent inhibiting the cutaneous capillary leakage induced by many marine venoms.

\section{Amine Contents in $A$. planci and A. plumosum Venoms}

HPLC analyses revealed that histamine was not contained in both $A$. planci and $A$. plumosum venoms although the cutaneous capillary leakage induced by these venoms was blocked by the antihistaminic, diphenhydramine. The absence of serotonin was also established. However, several amines were observed in both venoms; in addition to unknown amines, spermidine is probably present in $A$. planci venom and tryptamine and tyramine in $A$. plumosum venom. These amines may partly contribute to the cutaneous capillary damage and/or to other local effects in the skin.

\section{Histamine Release from Rat Mast Cells by $A$. planci Venom}

The histamine content in the mast cell suspension was determined to be $11.1 \pm 0.7 \mu \mathrm{g} / \mathrm{m} l$ (mean \pm S.D., $\mathrm{n}=5$ ). Fig. 1 shows that $A$. planci venom can release histamine from rat mast cells in a manner of dose-dependence. Preliminarily, severe destruction and degranulation of mast cells were 


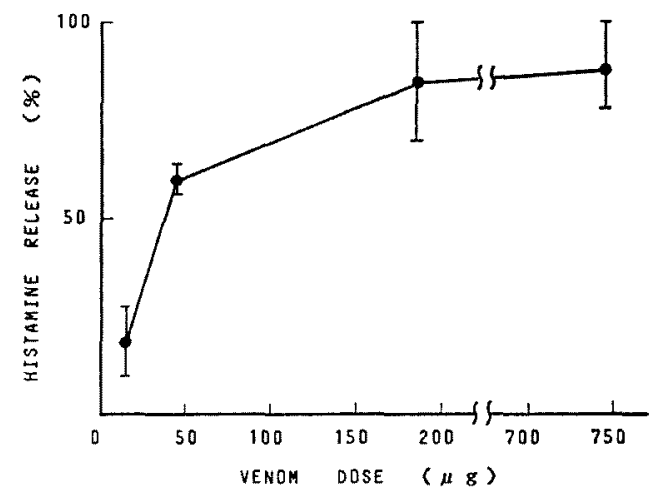

Fig. 1. Histamine release from rat mast cells by A. planci venom.

Results are expressed as the mean \pm S.D. $(n=3)$.

observed in the venom-treated rat mesentery. The presence of a histamine-releasing factor has also been reported in venom of the sea urchin Toxopneustes pileolus. ${ }^{7,8)}$

As described above, the capillary permeabilityincreasing activity of $A$. planci venom is blocked by antihistaminics but histamine is absent in the venom. It was, therefore, concluded that a histamine-releasing factor in the venom acts on mast cells (and other cells) and then the released histamine produces the cutaneous capillary leakage. This is probably true for $A$. plumosum venom although the presence of a histamine-releasing factor is not yet established.

It is well known that a variety of biological activities are exhibited by $A$. planci venom. ${ }^{9,10}$ Recently we have purified a lethal factor in $A$. planci venom and clarified its biological and physicochemical properties. ${ }^{11}$ ) The histamine-releasing factor detected in this study is apparently distinguishable from the lethal factor which has no substantial biological activities, except for lethal activity. In order to obtaine more knowledge about the local effects in the skin induced by $A$. planci stings, it is essential to disclose pro. perties of the histamine-releasing factor. However, it should be kept in mind that all of the local effects can not be explained by the histaminereleasing factor alone since histamine is not always responsible for the edema-formation.

\section{Acknowledgements}

This study was partly supported by a Grant-in. Aid from the Ministry of Education, Science and Culture of Japan. The authors are grateful to Mr. S. Katayama in our laboratory for the determination of amines by HPLC.

\section{References}

1) J. W. Burnett and G. J. Calton: Toxicon, 24, 614-617 (1986).

2) O. H. Lowry, N. J. Rosebrough, A. L. Farr, and R. J. Randall: J. Biol. Chem., 193, 265-275 (1951).

3) M. Yamakawa, M. Nozaki, and Z. Hokama: in "Animal, Plant, and Microbial Toxins" (ed. by A. Ohsaka, K. Hayashi, and Y. Sawai), Vol. 1, Plenum Press, New York and London, 1976, pp. 97-109.

4) H. Yamanaka, K. Shiomi, and T. Kikuchi: $J$. Food Sci., 52, 936-938 (1987),

5) S. Wiener: Med. J. Aust., 1, 620-627 (1959).

6) S. Wiener: Med. J. Aust., 2, 715-719 (1959).

7) A. Kimura and H. Nakagawa: Toxicon, 18, 689-693 (1980).

8) H. Nakagawa, A. Kimura, M. Takei, and K. Endo: Toxicon, 20, 1095-1097 (1982).

9) E. Taira, N. Tanahara, and M. Funatsu: Ryukyu Daigaku Nogakubu Gakujutsu Hokoku, No. 22, 203-213 (1975).

10) K. Shiomi, K. Itoh, H. Yamanaka, and T. Kikuchi: Nippon Suisan Gakkaishi, 51, 1151-1154 (1985).

11) K. Shiomi, S. Yamamoto, H. Yamanaka, and T. Kikuchi: Toxicon, 26, 1077-1083 (1988). 